\title{
Thin-film materials based on phthalocyanine derivatives: structure and physico-chemical properties
}

\author{
Alexandr Kazak $^{1,2,3, *}$, Margarita Marchenkova ${ }^{2,4}$, Antonina Smirnova ${ }^{1}$, Tatiana Dubinina ${ }^{5}$, \\ Alexey Seregin ${ }^{2,4}$, Alexandr Rogachev ${ }^{4}$, and Nadezhda Usol'tseva $^{1}$ \\ ${ }^{1}$ Nanomaterials Research Institute, Ivanovo State University, 153025 Ivanovo, Russia \\ ${ }^{2}$ Shubnikov Institute of Crystallography of Federal Scientific Research Center "Crystallography and \\ Photonics" of Russian Academy of Sciences, 119333 Moscow, Russia \\ ${ }^{3}$ Moscow Region State University, 141014 Mytishi, Russia \\ ${ }^{4}$ National Research Center "Kurchatov Institute", 123182 Moscow, Russia \\ ${ }^{5}$ Department of Chemistry, Lomonosov Moscow State University, 119991 Moscow, Russia
}

\begin{abstract}
In order to establish the effect of the molecular structure of mix-substituted phthalocyanine derivatives on its supramolecular organization in thin-films, the floating layers of three $\mathrm{A}_{3} \mathrm{~B}$-type phthalocyanine derivatives were obtained. Their supramolecular organization was determined and it was found that the studied compounds form homogeneous stable floating layers on the water surface. Structure parameters of floating layers depend both on the length of aliphatic substituents $\left(\mathrm{R}=\mathrm{C}_{n} \mathrm{H}_{2 n+1}\right)$ and the metal complexing agent. Ligands $\mathbf{I}$ and II form stable monolayer structures, which the layer packing periods increase with the elongation of aliphatic substituents: the lattice parameter (d) is 1.93 and $2.3 \mathrm{~nm}$ for ligands I $(n=6)$ and II $(n=8)$, correspondingly. During further compression of the formed monolayers, ligands I and II form stable bilayers, in which the arrangement of molecules remains similar to the structure of the previous monolayers. These bilayers contain minor inclusions of 3D aggregates. Metal complex III forms only stable monolayer $(\mathrm{d}=2.06 \mathrm{~nm})$, upon further compression of which 3Daggregates included in the monolayer are formed.
\end{abstract}

\section{Introduction}

The relationship between the molecular structure of phthalocyanine derivatives and their physical and physicochemical properties has been studied in sufficient detail. The use of hydrophobic substituents can increase their solubility in organic solvents and can lead to appearance of thermotropic or lyotropic mesomorphism [1]. Moreover, substituents in one molecule can be of various types (donor/acceptor, hydrophilic/hydrophobic, etc.) [2]. In recent decades, the new synthesized phthalocyanines have been of particular interest due to the combination of high thermal and chemical stability, lipophilicity and solubility in a wide range of solvents. The high solubility of phthalocyanines is important for many

*Corresponding author: alexkazak86@gmail.com 
reasons: for the study of optical properties, the creation of thin-layer structures using Langmuir methods, and their practical application. It was established that the number and type of substituents, as well as the place of substitution in the molecule, have a significant effect on the optical and mesomorphic properties [1,3].

Non-peripherally substituted phthalocyanines attract attention due to the fact that this arrangement of substituents shifts the absorption to the near-infrared region of the spectrum. For example, in a peripherally substituted phthalocyanine, the absorption spectrum is characterized by two intense bands: the Q-band with a maximum in the region of $670 \mathrm{~nm}$ and the B-band - close to the UV region - both associated with $\pi-\pi *$ transitions [4]. In non-peripherally substituted phthalocyanines, the $\lambda_{\max }$ position shifts by $50-70 \mathrm{~nm}$ to the long-wavelength region, since the alkoxy groups participate in the $\pi$ conjugated system of the phthalocyanine macrocycle. An increase in the number of alkoxy groups leads to a decrease in the energy of $\pi^{*}$-orbital. This leads to a long-wavelength shift in absorption [5]. In addition, it is peripherally substituted octaalkyloxy-phthalocyanines that have liquid crystalline properties, while non-peripherally substituted ones do not exhibit mesomorphism [6].

All above mentioned, together with the relative cheapness of synthesis, the possibility of forming metal complexes, which also affect the properties of phthalocyanines [1,2], the ability of phthalocyanine derivatives to form thin films on various substrates, attracted attention to these compounds as promising materials for many technologies: semiconductors, sensors, organic photovoltaics, etc. [7].

Organic photovoltaics is a promising alternative for expensive crystalline silicon solar cells in the field of renewable energy due to its low cost, the possibility of creating large areas on flexible substrates, less weight. Organic photovoltaic cells typically use compositions of key compounds. Each component of such a composition has its own responsibility: light absorbing dye, hole conductor, electron acceptor.

For example, the so-called "small" organic molecules solar cells may contain phthalocyanines or porphyrins as dyes, polymers such as MDMO-PPV or P3HT as donor phase and simultaneously glassy materials, and fullerenes or perylene derivatives as electron acceptors [8].

This type of organic solar cells with a bulk heterojunction [9] makes it possible to convert light energy with an efficiency of about $7 \%$. The main modern trend in increasing the efficiency of solar cells is the design and synthesis of new organic low molecular weight components such as dendrimers, star-shaped compounds and phthalocyanine derivatives. The advantage of these materials is a precisely established molecular structure with certain molecular weight, fairly simple synthesis and possibility of production scaling, a better understanding of the relationship between structure and properties, etc. [10].

However, to obtain new highly effective functional materials based on nanoscale thin films, it is necessary to control their structure, including an assessment of the uniformity of the films. [11]. Therefore, to obtain floating layers, we used the Langmuir method, which allows one to form structured one-component layers with molecular control of their thickness [12-16]. In addition, previous studies have shown that organic light emitting diodes (OLEDs) based on Langmuir-Blodgett films have better performance characteristics than OLEDs obtained by other methods [17]. At the same time, the study of floating layers of phthalocyanine derivatives is necessary, since the structure and properties of thin-film materials usually depend on the supramolecular organization of floating layers [18-22].

Mix-substituted "push-pull" phthalocyanines of $\mathrm{A}_{3} \mathrm{~B}$-type have attracted our attention as promising low molecular weight dyes for organic solar cells. Since they contain both electron donor and electron withdrawing substituents in one molecule, they have a polarized structure, which favors the formation of columnar mesophases that can undergo glass transition without crystallization upon cooling [23]. 
Thus, the aim of this work was a comprehensive study of the influence of molecular structure features on the supramolecular organization of three mix-substituted phthalocyanine derivatives (Fig. 1) in floating layers and the subsequent production of effective thin-film materials that could be used in photovoltaics.

\section{Materials and methods}

The objects of this study were the ligands of the mix-substituted phthalocyanine derivative (compounds I, II) with four chlorine atoms in the "B"-fragment and the holmium complex of the mix-substituted phthalocyanine derivative with two chlorine atoms in the fragment "B" (compound III, Fig. 1). The synthesis of the compounds was carried out according to the methods described previously [24, 25]. Previously we showed [24, 26] that these compounds possess liquid crystalline properties, exhibiting in the temperature range from 100 to $200{ }^{\circ} \mathrm{C}$ a columnar two-dimensionally ordered mesophase with typical texture. Above $200{ }^{\circ} \mathrm{C}$, without transition to an isotropic state, the substance begins to decompose. Upon cooling below $100{ }^{\circ} \mathrm{C}$, the compounds vitrify maintaining the mesophase texture.

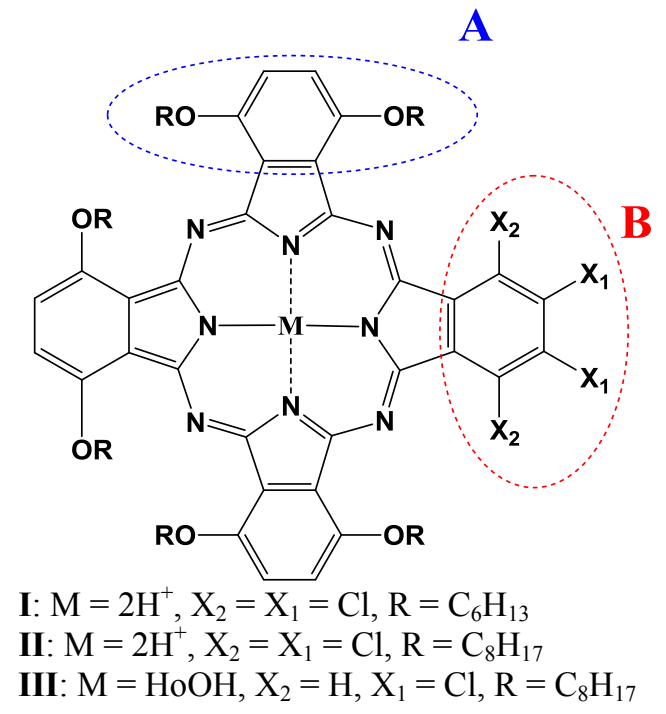

Fig. 1. Structural formula of the studied phthalocyanine derivatives.

Models of the phthalocyanine molecules and its monomolecular layer on the water surface, as well as the calculation of their geometric characteristics, were performed using HyperChem 8.0 software (MM+ method), as it was described earlier [27]. These data were used to determine the type of molecular packing in floating layers.

Floating layers were formed from a chloroform solution $(\mathrm{C}=0.0067 \mathrm{wt}$ \%, where $\mathrm{C}$ is the mass fraction of the dissolved phthalocyanine). The layers were obtained with the use of Nima 601A, KSV mini trough or KSV 5000 (Finland) troughs. The compression rate was 6 $\mathrm{cm}^{2} / \mathrm{min}$. Water (with resistivity $\rho=18 \mathrm{M} \Omega \cdot \mathrm{cm}$ ) used as a subphase was purified by Millipore Simplicity 158 systems. The initial coverage degree $(c)$ of the water surface with phthalocyanine molecules was calculated according to the method published in [28].

Layer formation at the water/air interface was studied in situ by Brewster microscopy method (BAM Optrel 3000 microscope, KSV Instruments, Finland). The HeNe laser with a radiation wavelength of $633 \mathrm{~nm}$ and a power of $10 \mathrm{~mW}$ was used as a light source in this setup. The goniometer of the microscope set the angle of laser incidence beam in the range from 45 to $75^{\circ}$ with an accuracy of $0.01^{\circ}$. To obtain polarized light and contrast image, 
high-precision polarizers with a polarization ratio of $10^{-8}$ were used. The image was enlarged using interchangeable lenses $(\times 5, \times 10, \times 20)$ and recorded by a computercontrolled high-quality camera with a resolution of $768 \times 72$ pixels, the spatial resolution was $2 \mu \mathrm{m}$.

Structural organization of floating layers was studied by diffraction in sliding geometry (GID - grazing incidence diffraction) and reflectometry (XRR - X-ray reflectivity) methods. GID experiments were carried out on "Langmuir" beamline at the Kurchatov synchrotron radiation source. Radiation from a bending magnet with an energy of $13 \mathrm{keV}$ was used for the experiments. The pair of flat mirrors was used to incline the beam to water surface and the incidence angle was 0.8 of critical angle of the total external reflection for water. The data was collected by 0D scintillator detector Radicon SCSD4 and 1D detector Mythen $21 \mathrm{kX}$. For horizontal collimation of diffracted beam, the Soller slots with an angular aperture of $2 \mathrm{mrad}$ were used. To reduce scattering in air, as well as evaporation of liquid from the Langmuir trough, all measurements were carried out in the humid helium atmosphere. Since at room temperature monolayers are actually 2D-“powder", i.e. superposition of two-dimensional crystallites randomly oriented on the water surface, the diffraction pattern was scanned only at an angle of $2 \theta$ in the film plane ( $q_{x y}-$ scanning). The qualitative analysis of diffraction pattern was carried out according to the standard (three-dimensional) powder diffraction scheme, when the angular positions of the Bragg peaks $2 \theta_{h k}$, corresponding to the vectors of the two-dimensional reciprocal lattice, determine the distances between the chains of molecules $d_{h k}$.

XRR measurements were carried out by the liquid interfaces scattering apparatus LISA at the P08 beamline (PETRA III, DESY, Germany) [29]. The size of the focused X-ray beam $(18 \mathrm{keV})$ was $500 \mu \mathrm{m} \times 8 \mu \mathrm{m}$ at the sample position. The scattering pattern was collected on a hybride photon counting pixel detector (Dectris Eiger 1M, $75 \mathrm{~mm} \times 75 \mathrm{~mm}$ pixel size) at $1.2 \mathrm{~m}$ sample-detector distance.

\section{Results and discussion}

\subsection{Modeling of floating layers}

A model of a monomolecular floating layer placed on the water surface was obtained after optimization by the molecular mechanics method (Fig. 2). When simulating the floating layer, phthalocyanine molecules were situated in one plane. Such location corresponds to a monolayer package. The formed monolayer was placed on the preliminary modeled water surface.

According to the data obtained, the model area of the elementary cell of the monolayer was calculated. If the structure of the phthalocyanine molecule is assumed to be flat, the area per one molecule in the densest face-on monomolecular packing is $5.4 \mathrm{~nm}^{2}$ for compounds II and III and it is equal to $4.5 \mathrm{~nm}^{2}$ for compound I. When lateral substituents are displaced from the phthalocyanine macrocycle plane, the area per one molecule in the densest face-on monolayer can be reduced to $1.6 \mathrm{~nm}^{2}$. The calculated area size was then compared with the areas obtained in the experiment, and on the basis of these results, a conclusion about the layer structure was drawn.

\subsection{Supramolecular organization of floating layers}

Structure parameters of floating layers depend both on the length of aliphatic substituents and on the metal complexing agent. It was found that the studied ligands $\mathbf{I}\left(\mathrm{R}=\mathrm{C}_{6} \mathrm{H}_{13}\right)$ and II $\left(\mathrm{R}=\mathrm{C}_{8} \mathrm{H}_{17}\right)$ form monolayer structures on the water surface starting from $\mathrm{A}_{\mathrm{mol}}=7 \mathrm{HM}^{2}$. 


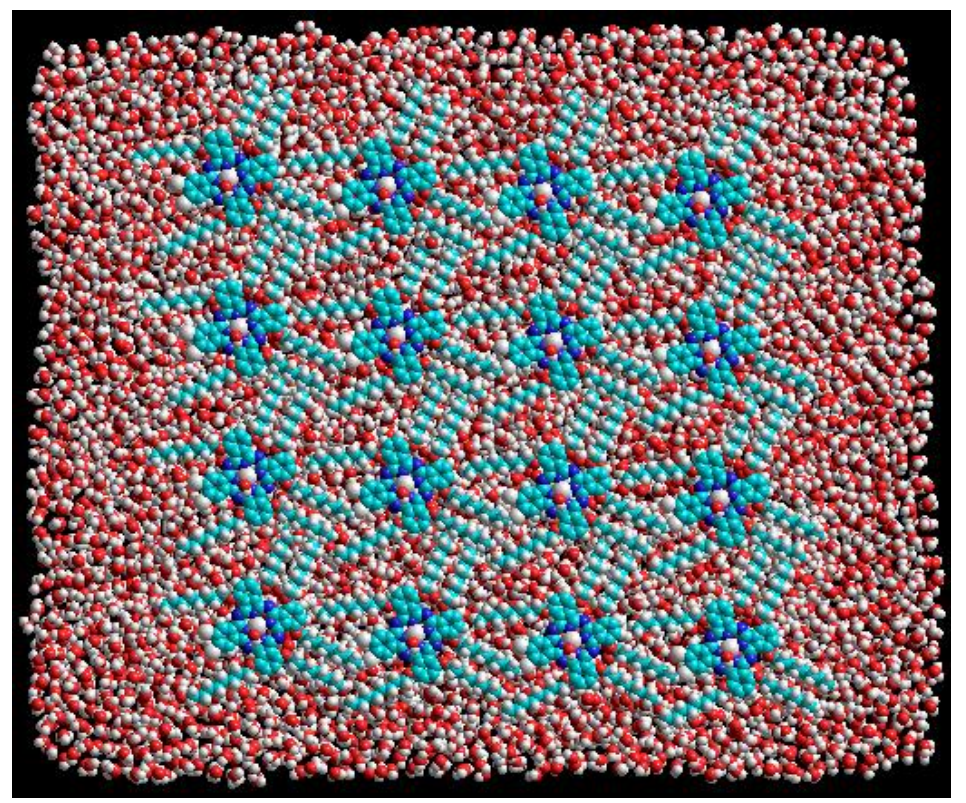

a

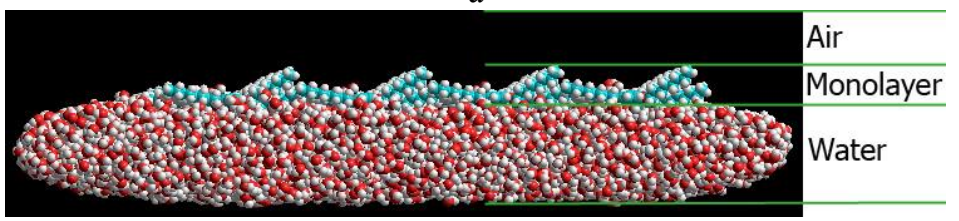

b

Fig. 2. Model of floating monolayer packing of compound III placed on the water surface before the lateral substituents were displaced from the macrocycle plane: a) top view, b) side view.

The molecules arrange with their macrocycle plane parallel to the water surface. Each of ligands has just one crystalline phase, but with different lattice periods: $\mathrm{d}=1.93 \mathrm{~nm}-$ for compound I (Fig. 3) and d =2.3 nm - for compound II (Fig. 4). It is likely that an increase in the length of aliphatic substituents affects the increase in the lattice period.

The formation of additional crystalline phases does not occur, possibly due to the presence of long aliphatic substituents in the phthalocyanine molecules, which sterically disrupt the interaction of macrocycles and, thus, prevent the formation of any crystalline phases that are different from the phase with a flat macrocycle on the water surface. Starting from the area per one molecule $\mathrm{A}_{\text {mol }}=1.65 \mathrm{~nm}^{2}$, two structures were simultaneously formed: a monolayer with a flat arrangement of molecules and 3D aggregates. In this case, the diffraction pattern does not undergo significant changes, which may mean the preservation of the predominantly flat arrangement of molecules. With further preloading of the barrier, stable bilayers are formed. The arrangement of molecules in them is preserved like in a monolayer packing. It was shown that the ligand with longer aliphatic substituents (compound II) forms more structured layers, compared to compound I.

When $\mathrm{HoOH}$ complexing agent is introduced into molecular structure of III, despite the fact that length of the aliphatic substituent $\mathrm{R}=\mathrm{C}_{8} \mathrm{H}_{17}$, the monolayer lattice period decreases $(\mathrm{d}=2.06 \mathrm{~nm}$, Fig. 5) in comparison with the ligand II. Unlike ligands I and II, the complex III does not form bilayer structures during compression. We assume that the presence in the phthalocyanine III of HoOH-group, which is immersed into the water subphase when the molecule is placed onto water, can be an anchoring factor that prevents the formation of a bilayer structure. The conditions required to form the stable ordered 
monomolecular floating layer for compound III were determined as follows: the initial degree of coating of the water surface is $18 \%$, the compression rate of the barriers is $6 \mathrm{~cm}^{2} / \mathrm{min}$, the surface pressure is $0.4 \mathrm{mN} / \mathrm{m}$ and the area per molecule is $3.9 \mathrm{~nm}^{2}$.

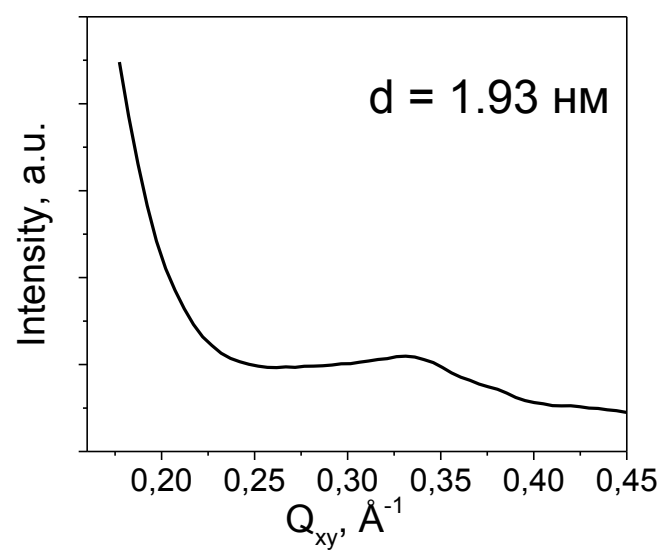

Fig. 3. GID curve of the floating layer of compound $\mathbf{I}$.

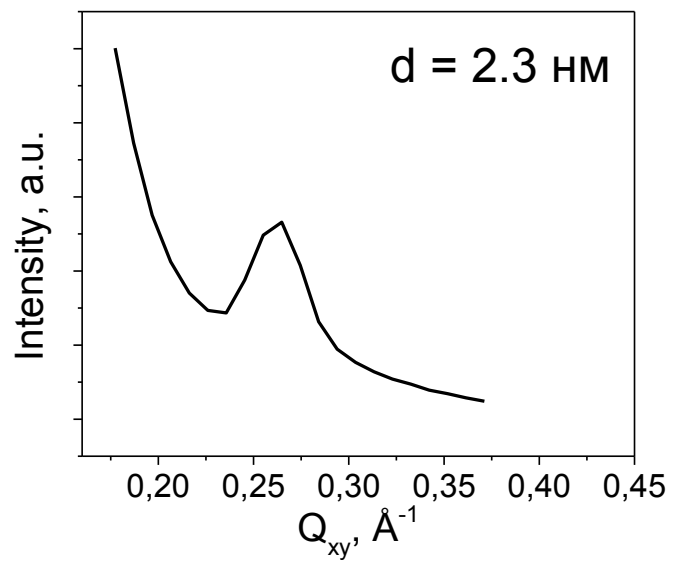

Fig. 4. GID curve of the floating layer of compound II.

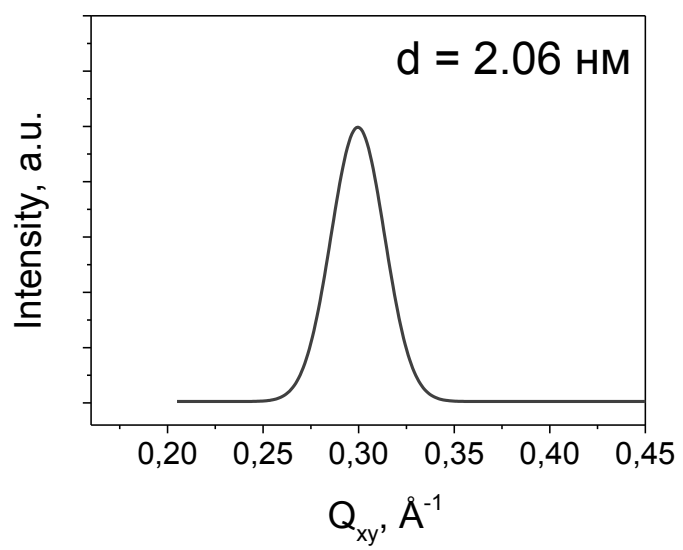

Fig. 5. GID curve of the floating layer of compound III. 


\section{Conclusion}

As a result of the performed comprehensive theoretical and experimental study, it was found for all the studied compounds that at the beginning of the floating layer formation the aliphatic substituents are smoothly displaced from the macrocycle plane into the air phase.

Subsequently, when $\mathrm{A}_{\text {mol }}$ decreases, compounds I and II form stable bilayer structures with inclusion of 3D aggregates. The packing period of the molecules in the layer increases with elongation of aliphatic substituents. The metal complex III generates just only stable monolayers, upon compression of which the molecular packing in the monolayer is compacted and 3D aggregates included in the monolayer are formed.

Formation conditions of a stable monolayer for the complex III were also established as following: the initial degree of surface coating is $18 \%$, the layer compression rate is $6 \mathrm{~cm}^{2} / \mathrm{min}$, the surface pressure is $0.4 \mathrm{mN} / \mathrm{m}$, the area per molecule in the layer is $3.9 \mathrm{~nm}^{2}$.

This work was supported by the program of the Ministry of Education and Science of the Russian Federation as part of a state assignment to Ivanovo State University for research work (Grant No. 16.1037.2017 / 4.6) and was partially supported by the Russian Foundation for Basic Research (grants No 19-03-00763a, No 19-57-04002bel_mol_a) and by the grant of the President of the Russian Federation for young scientists (No MK-3767.2019.9).

\section{References}

1. N.V. Usol'tseva, Liquid crystalline properties of porphyrins and related compounds, Ch. 7, In: Advances of porphyrin chemistry. Vol. 2. M.I. Bazanov, B.D. Berezin, D.B. Berezin et al. (St.-Petersburgh, 1999)

2. M. Ahmida, R. Larocque, M.S. Ahmed, A. Vacaru, B. Donnio, D. Guillon, S.H. Eichhorn, Halide effect in electron rich and deficient discotic phthalocyanines, J. Mater. Chem, v. 20(7), pp 1292-1303 (2010)

3. A.N. Cammidge, R.J. Bushby, Synthesis and structural features, in Handbook of Liquid Crystals, v 2B, pp. 693-748, edited by D. Demus, J. Goodby, G.W. Gray, H.-W. Spiess, V. Vill, (New York, Chichester, Brisbane, Singapore, Toronto, Wiley-VCH, 1998)

4. G. De la Torre, P. Vázques, F. Agulló-López, T. Torres, Phthalocyanines and related compounds: organic targets for nonlinear optical application, J. Mater. Chem, v. 8, pp. 1671-1683 (1998)

5. Y. Wu, H. Tian, K. Chen, Y. Liu, D. Zhu, Synthesis and properties of soluble phthalocyanines containing tetra- or octa-alkyloxy substituents, Dyes and Pigments, v. 37(4), pp. 317-325 (1998)

6. M.J. Cook, M.F. Daniel, K.J. Harrison, N.B. McKeown, A.J. Thomson 1,4,8,11,15,18,22,25-Octa-alkyl phthalocyanines: new discotic liquid crystal materials, J. Chem. Soc., Chem. Commun, pp. 1086-1088 (1987)

7. D. Wöhrle, G. Schnurpfeil, S.G. Makarov, A. Kazarin, O.N. Suvorova, Practical application of phthalocyanines - from dyes and pigments to materials for optical, electronic and photo-electronic devices, Macroheterocycles, v. 5(3), pp. 191-202 (2012)

8. B. Kippelen, J.-L. Bredas, Organic photovoltaics, Energy Environ. Sci, v. 2, pp. 251261 (2009)

9. E. Moulin, E. Busseron, N. Giuseppone, Self-assembled Supramolecular Materials in Organic Electronics, in RSC Smart Materials No. 12. Supramolecular Materials for Opto-Electronics, pp. 1-52, edited by N. Koch, (The Royal Society of Chemistry, 2015) 
10. Yu.N. Luponosov, J. Min, A.N. Solodukhin, O.V. Kozlov, M.A. Obrezkova, S.M. Peregudova, T. Ameri, S.N. Chvalun, M.S. Pshenichnikov, C.J. Brabec, S.A. Ponomarenko, Effects of electron-withdrawing group and electron-donating core combinations on physical properties and photovoltaic performance in $D$ - $\pi$-A starshaped small molecules, Organic Electronics, v. 32, pp. 157-168 (2016)

11. R.K. Gupta, V. Manjuladevi, C. Karthik, K. Choudhary, Thin films of discotic liquid crystals and their applications, Liq. Cryst., v. 43(13-15), pp. 2079-2091 (2016)

12. Z. Guennouni, F. Cousin, M.C. Fauré, P. Perrin, D. Limagne, O. Konovalov, M. Goldmann, Self-organization of polystyrene-b-polyacrylic acid (PS-b-PAA) monolayer at the air/water interface: a process driven by the release of the solvent spreading, Langmuir, v. 32(8), pp. 1971-1980 (2016)

13. Yu.A. Dyakova, E.I. Suvorova, A.S. Orekhov, A.S. Orekhov, A.S. Alekseev, R.V. Gainutdinov, V.V. Klechkovskaya, E.Yu. Tereschenko, N.V. Tkachenko, H. Lemmetyinen, L.A. Feigin, M.V. Kovalchuk, Study of structural order in porphyrinfullerene dyad ZnDHD6ee monolayers by electron diffraction and atomic force microscopy, Crystallography Reports, v. 58(6), pp. 927-933 (2013)

14. A.V. Kazak, N.V. Usol'tseva, A.I. Smirnova, V.V. Bodnarchuk, S.N. Sul'yanov, S.V. Yablonskii, Structure and physicochemical properties of thin film photosemiconductor cells based on porphine derivatives, Crystallography Reports, v. 61(3), pp. 493-498 (2016)

15. R. Dhrubojyoti, D.N. Mani, N. Shakti, P.S. Gupta, Comparative study of optical, structural and electrical properties of zinc phthalocyanine Langmuir-Blodgett thin film on annealing, RSC Adv., v. 4(80), pp. 42514-42522 (2014)

16. A.V. Kazak, N.V. Usol'tseva, A.I. Smirnova, Yu.A. Dyakova, M.A. Marchenkova, B.V. Nabatov, E.Yu. Tereschenko, I.V. Kholodkov, Optical properties and supramolecular organization of mix-substituted phthalocyanine holmium complex in Langmuir-Schaefer films, Macroheterocycles, v. 8(3), pp. 284-289 (2015)

17. Y. Yang, X. Yang, W. Yang, S. Li, J. Xu, Y. Jiang, Ordered and ultrathin reduced graphene oxide LB films as hole injection layers for organic light-emitting diode, Nanoscale Res. Lett., v. 9, pp. 537-6 (2014)

18. A.S. Chumakov, A.J. Al-Alwani, I.A. Gorbachev, A.V. Ermakov, A.A. Kletsov, E.G. Glukhovskoy, A.V. Kazak, N.V. Usol'tseva, S.N. Shtykov, Temperature and mixing ratio effects in the formation of $\mathrm{CdSe} / \mathrm{CdS} / \mathrm{ZnS}$ quantum dots with 4'-n-octyl-4-pcyanobiphenyl thin films, BioNanoSci., v. 7(4), pp. 666-671 (2017)

19. A.J. Al-Alwani, K.I. Kosolapova, A.S. Chumakov, V.O. Lukyanova, I.A. Gorbachev, A.V. Kazak, A.I. Smirnova, S.N. Shtykov, N.V. Usol'tseva, E.G. Glukhovskoy, Studying of surfactant excess separation from non-aqueous quantum dots solution on its monolayer formation process, BioNanoSci., v. 8(4), pp. 1081-1086 (2018)

20. A.V. Kazak, N.V. Usol'tseva, V.V. Bykova, A.S. Semeikin, S.G. Yudin, Influence of meso-substituted porphyrins molecular structure on their self-organization in floating layers, Mol. Cryst. Liq. Cryst., v. 541(1), pp. 28-34 (2011)

21. A.J.K. Al-Alwani, A.S. Chumakov, O.A. Shinkarenko, I.A. Gorbachev, M.V. Pozharov, S. Venig, E.G. Glukhovskoy, Formation and optoelectronic properties of graphene sheets with $\mathrm{CdSe} / \mathrm{CdS} / \mathrm{ZnS}$ quantum dots monolayer formed by LangmuirSchaefer hybrid method, Appl. Surf. Sci., v. 424(2), pp. 222-227 (2017)

22. A. Kolker, V. Erokhin, N. Borovkov, Solvent-assisted interfacial assembly of copper tetra-(tert-butyl)-phthalocyanine into ultrathin films, J. Phys. Chem. C, v. 120(23), pp. 12706-12712 (2016) 
23. N.V. Usol'tseva, A.I. Smirnova, A.V. Kazak, N.I. Giricheva, N.E. Galanin, G.P. Shaposhnikov, V.V. Bodnarchuk, S.V. Yablonskii, Mix-substituted phthalocyanines of a "push-pull"-type and their metal complexes as prospective nanostructured materials for optoelectronics, Opto-Electronics Review, v. 25(2), pp. 127-136 (2017)

24. N.E. Galanin, G.P. Shaposhnikov, A.I. Smirnova, A.V. Kazak, N.V. Usol'tseva, Synthesis, spectral and mesomorphic properties of mix-substituted phthalocyanines based on 3,6-dioctyloxyphthalonitrile and 4,5-dichlorophthalonitrile, and their holmium complexes, Liquid Crystals and their Application, v. 14(4), pp. 74-84 (2014)

25. N.E. Galanin, G.P. Shaposhnikov, Synthesis and spectral properties of unsymmetrical phthalocyanines from 3,6-dioctyloxyphthalonitrile and 3,4,5,6-tetrachlorophthalonitrile, Russian Journal of General Chemistry, v. 82(10), pp. 1734-1739 (2012)

26. N.V. Usol'tseva, A.V. Kazak, I.Yu. Luk'yanov, V.V. Sotsky, A.I. Smirnova, S.G. Yudin, G.P. Shaposhnikov, N.E. Galanin, Influence of molecular structure peculiarities of phthalocyanine derivatives on their supramolecular organization and properties in the bulk and thin films, Phase Transitions: A Multinational Journal, v. 87(8), pp. 801813 (2014)

27. A.V. Kazak, N.V. Usol'tseva, V.V. Bykova, A.S. Semeikin, S.G. Yudin, Comparative analysis of supramolecular organization in floating layers of meso-substituted tetraphenylporphyrines, Liq. Cryst. and their Appl., No 4, pp. 90-97 (2010)

28. A.V. Kazak, L.N. Zhukova, M.I. Kovaleva, D.N. Chausov, M.M. Kuznetsov, G.F. Gabdulsadykova, Self-organization of azo dye KD-2 in floating layers and LangmuirSchaefer films, Liq. Cryst. and their Appl., v. 18(3), pp. 74-81 (2018)

29. B.M. Murphy, M. Greve, B. Runge, C.T. Koops, A. Elsen, J. Stettner, O.H. Seeck, O.M. Magnussen, A novel X-ray diffractometer for studies of liquid-liquid interfaces, J. Synchrotron Radiat., v. 21, pp. 45-56 (2014) 